symptoms were attributable to psychogenic causes. We do feel, however, that there is sufficient evidence in our data to support the notion that symptoms may be attributable to psychogenic causes in appreciable numbers of patients - greater numbers than we were able to prove had specific food intolerance.

J F MACKENZIE, I CALDER, and LOUISE BENSON Royal Infirmary, Glasgow.

\section{Drug therapy and perforated peptic ulcer}

SIR, - We read with interest the recent paper by Collier and Pain (Gut 1985; 26: 359-63) concerning drug therapy and perforated peptic ulcer. A recent survey in Oxford confirms that the incidence of perforation has changed little since the introduction of cimetidine. As in other studies perforation in patients currently receiving cimetidine was also observed.

Although Collier and Pain's review provides confirmatory evidence of an association between non-steroidal anti-inflammatory drugs and peptic ulcer perforation, details of individual drugs which might have a particularly strong association with perforation were not given. Case controls were not available in the Oxford study but over half the $26 \%$ patients receiving non-steroidal anti-inflammatory drugs at the time of perforation were taking indomethacin. A report from Exeter ${ }^{2}$ utilising case controls has confirmed that indomethacin is associated with an increased risk of perforation of duodenal ulcers.

All retrospective studies are liable to underestimate the number of patients taking non-steroidal anti-inflammatory drugs. Jorgenson's retrospective surve $^{3}$ showed that less than $20 \%$ of patients suffering a perforation had taken drugs known to be associated with peptic ulceration while his limited prospective study showed the true incidence to be over $80 \%$. Having established an association between non-steroidal anti-inflammatory drugs and perforated peptic ulcer further prospective studies with case controls are now essential to assess accurately the hazards associated with each agent. The availability of this information would enable the risks of individual drugs to be considered before they are prescribed.

Surgical Unit,

R M WATKINS, A R DENNISON, and J COLLIN

Westminster Hospital, London

and Nuffield Department of Surgery,

John Radcliffe Hospital,

Headington, Oxford.

\section{References}

1 Watkins RM, Dennison AR, Collin J. What has happened to perforated peptic ulcer? Br J Surg 1984; 71: 774-6.

2 Thompson MR. Indomethacin and perforated duodenal ulcer. Br Med J 1980; 280: 448.

3 Jorgenson TG. Drug consumption before perforation of a peptic ulcer. Br J Surg 1977; 64: 247-9.

\section{Reply}

SIR,-We are pleased to be given the opportunity to reply to the letter of Watkins, Dennison, and Collin. The frequency of ingestion of non-steroidal antiinflammatory drugs (NSAID) is given in the Table.

Table Frequency of ingestion of NSAID in patients with perforated peptic ulcers according to specified drugs

\begin{tabular}{lll}
\hline NSAID & $\begin{array}{l}\text { Perforated } \\
\text { duodenal ulcers }\end{array}$ & $\begin{array}{l}\text { Perforated } \\
\text { gastric ulcers }\end{array}$ \\
\hline Indomethacin & 31 & 10 \\
Phenylbutzone & 10 & 1 \\
Aspirin & 8 & 1 \\
Piroxicam & 5 & 4 \\
Ketoprofen & 5 & 1 \\
Indomethacin suppos. & 3 & 3 \\
Ibuprofen & 4 & 1 \\
Benorylate & 3 & 1 \\
Diflunisal & 2 & 1 \\
Mefenamic acid & 2 & 0 \\
Others & 9 & 4 \\
\hline
\end{tabular}

Some patients were taking more than one NSAID.

NSAID $=$ non-steroidal anti-inflammatory drugs.

We were unable to obtain figures for the number of individual preparations prescribed within this regional health authority from the DHSS, for reasons of commercial secrecy, and therefore correlations for individual drugs were not assessed. Thus in our paper ${ }^{1}$ we compared the annual number of patients taking NSAID in specified age/sex groups and the annual number of prescriptions for all NSAIDs issued in this region, and showed a significant correlation in patients aged over 65, especially women. It is interesting, however, to note how frequently piroxicam was the NSAID being taken in view of the fact that it was only introduced during the latter three years of our 10 year study.

The late Morton Grossman wrote that 'the gun must be loaded in order for an explosion to occur when salicylates pull the trigger' 2 it would appear that certain NSAIDs are more 'trigger happy than others'; and furthermore that being over 65 and a woman makes it more likely that the gun is loaded.

D StJ COLLIER and $\mathrm{J}$ A PAIN 